\title{
Loop-Like Process of Knowledge Transfer: Diffusion of New Technology in the International Civil Aviation Domain
}

\author{
Yoshinobu Nakanishi
}

\begin{abstract}
In past studies, the knowledge transfer process was illustrated as a four-stage serial process comprising the following stages: initiation, implementation, ramp-up, and integration. However, actual cases on the knowledge transfer process indicated a deviation from this model. This study proposes a modified process model by collecting and analyzing knowledge transfer data on new technology in the civil aviation domain. In the proposed modified model, the ramp-up stage (in which the transferred knowledge is utilized) and the integration stage (in which the knowledge is integrated into an organizational routine) have a reciprocal relationship. In other words, in the knowledge transfer process, (1) initial routine is established by the recipient of the knowledge, (2) transferred knowledge is utilized according to the initial routine, and (3) the routine is continuously amended based on feedback obtained through the usage of the knowledge. Although this modified knowledge transfer process needs to be validated with empirical research, it seems to provide a better explanation for the actual knowledge transfer process.
\end{abstract}

Index Terms-Knowledge transfer, organizational learning, routine, unlearning, accountability.

\section{INTRODUCTION}

In modern businesses, knowledge is regarded as the source of competitive advantage [1]-[3]. Knowledge is not only essential for production [2], but is also the most important means of production [1]. However, in present times, knowledge, once obtained, rapidly becomes obsolete. Therefore, it is essential to continuously obtain and apply useful knowledge [4]. Therefore, knowledge transfer between organizations has been studied in management science since the 1990s to analyze the factors that promote or prevent knowledge transfer.

Knowledge transfer comprises of several stages. Szulanski proposes a four-stage model of knowledge transfer comprising the following stages: initiation, implementation, ramp-up, and integration [5]. In this model, it is assumed that each stage occurs serially in the model.

However, it seems that actual knowledge transfer cases indicate a deviation from this model [6]. Therefore, in this study, data on knowledge transfer relating to new technology in the civil aviation domain were collected and analyzed to review the four-stage process model of knowledge transfer in real organizational situations.

Manuscript received September 21, 2013; revised November 22, 2013.

Yoshinobu Nakanishi is with the Graduate School of Business Administration, Kobe University, Kobe, Japan (e-mail: 090b408b@ stu.kobe-u.ac.jp).
For this purpose, the next chapter begins with a review of past studies, especially those relating to the process and components of knowledge transfer. Through this review of past studies, knowledge transfer theory and organizational learning theory are compared to facilitate the re-definition of knowledge transfer process. Then, the details relating to the data collection and analysis are presented. Finally, the four-stage process model is reviewed and a modified process model is proposed.

\section{Review OF PASt Studies}

As a preparation for research, this chapter first evaluates the definition of knowledge transfer. Then, it focuses on the analysis of the components of knowledge transfer and the four-stage process model of knowledge transfer [5], [7].

\section{A. Definition of Knowledge Transfer}

Argote et al. [8] define knowledge transfer by an organization as "the process through which one unit (e.g., individual, group, department, division) is affected by the experience of another" (pp. 3). This definition implies that knowledge transfer includes two basic elements: migration of knowledge from a source to the recipient organization and the effect of the knowledge on the recipient. Similarly, van Wijk et al. [9] define knowledge transfer as "the process through which organizational actors - teams, units, or organizations - exchange, receive, and are influenced by the experience and knowledge of others" (pp. 832). This definition again implies that being influenced by the knowledge is included in the process of knowledge transfer. As suggested in these definitions, it is commonly recognized that a recipient is influenced by the transferred knowledge during the knowledge transfer process.

Such influence includes the usage of knowledge obtained. For example, Darr \& Kurtzberg [10] regard the actual usage of new knowledge as the evidence of occurrence of knowledge transfer. Furthermore, Szulanski [6] defines knowledge transfer as "a process in which an organization recreates and maintains a complex, causally ambiguous set of routines in a new setting" (pp. 10). Here, it is emphasized that the transferred knowledge must be modified, or even recreated, to reflect the context surrounding the recipient, since the transferred knowledge cannot be used without alteration in a context different from that of the source. Then, the knowledge is integrated into an organizational routine, such as "the forms, rules, procedures, conventions, strategies, and technologies around which organizations are constructed and through which they operate" [11] (pp. 320). 


\section{B. Components of Knowledge Transfer}

This section helps understand the concept of knowledge transfer by discussing and explaining its components. Pérez-Nordtvedt et al. [12] use communication theory to show that knowledge transfer comprises source, recipient knowledge, and channel. However, this explanation does not cover all aspects of knowledge transfer, since it does not include the usage of knowledge, which is the stage emphasized by Argote et al. [8], Szulanski [7], and van Wijk [9]. This point is critical to the discussion of knowledge transfer. Knowledge transfer as explained by Pérez-Nordtvedt et al. [12] only deals with the transmission of information, but not knowledge.

Knowledge is different from information and data. Knowledge must relate to the belief and commitment of actors and reflect the viewpoints, intention, and objectives of actors [13]. However, this fact is not implied in the explanation provided by Pérez-Nordtvedt et al. [12].

Zack [14] briefly summarizes the discussion on data, information, and knowledge as follows. Data represent observations or facts out of context that are, therefore, not directly meaningful. Information results from the placement of data within a meaningful context, often in the form of a message. Knowledge is what we come to believe and value based on meaningfully organized accumulation of information (messages) through experience, communication, or inference.

Considering the discussion above, it will be more appropriate to assume a model of knowledge transfer that includes the stages for usage of knowledge and integration of transferred knowledge into routine. This is important because data must be applied in a context with belief, (thus resulting in experience) and integration of knowledge into routine is essential for its accumulation within an organization.

Thus, in this article, knowledge transfer is defined as " $a$ process in which knowledge is transferred from a source to a recipient via some channel, such that the knowledge influences the outcome of the recipient, and is integrated into its routine." This definition implies that knowledge transfer comprises several components such as source, recipient, channel, knowledge, outcome, routine, and context.

\section{Four-Stage Process Model of Knowledge Transfer [5]}

The components of knowledge transfer play specific roles in the related stages in the process. The knowledge transfer process model by Szulanski [5] comprises four stages-initiation, implementation, ramp-up, and integration.

In the initiation stage, related organizations, which are sources and recipients of knowledge, take actions to initiate transfer. Identification of the need to transfer is an example of a factor that is included at this stage.

Once the organizations decide to initiate the knowledge transfer, the implementation stage begins. In this stage, knowledge is transferred from the source to the recipient through an established channel. The relationship between the source and the recipient influences the efficiency of transfer.

Then, the transferred knowledge is applied in practice by the recipient to produce an outcome. The efficiency of the recipient improves with the continuous application of knowledge. This is the ramp-up stage. During this stage, the transferred knowledge is altered, or even recreated, to be adapted to the context surrounding the recipient.

Following the satisfactory application of transferred knowledge, the integration stage begins, in which the recipient organization establishes its routine based on the transferred knowledge and feedback received from its application.

Fig. 1 illustrates the four-stage knowledge transfer process as well as the components of knowledge transfer discussed in section B.
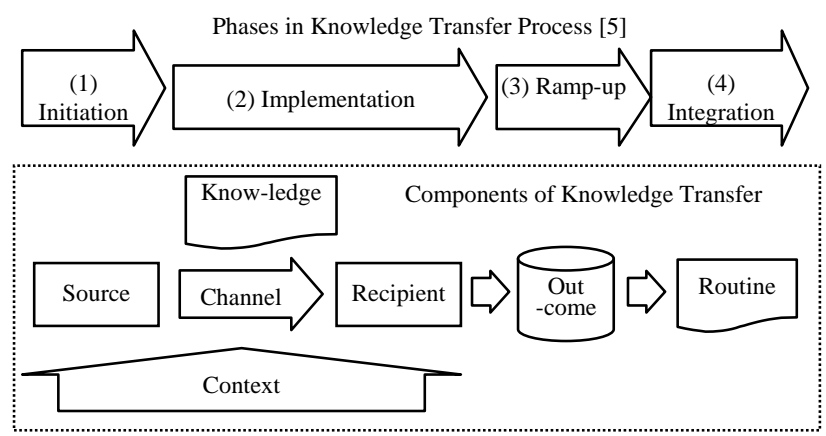

Fig. 1. The process and components of knowledge transfer process

As such, this four-stage process assumes a serial, one-way process of knowledge transfer. Szulanski [5] explained that this process had been developed on the basis of the review of empirical studies in various domains, such as diffusion of innovation, social change, technology transfer, and implementation of technology. A number of research studies cite this work by Szulanski (e.g., [8]-[10], [12], [15]).

\section{Organizational Learning and Knowledge Transfer}

The preceding section introduced a key term, namely, "routine." It seems that an understanding of routine is important for the study of the knowledge transfer process. However, there is a paucity of research on the role of routine in the knowledge transfer theory.

In contrast, formation and discarding of routine has been thoroughly studied in the domain of organizational learning [16]. Therefore, knowledge transfer and organizational learning (as research subjects) and their related research domains are reviewed and compared in this section for an improved understanding of routine.

First, comparison is made between knowledge transfer and organizational learning as organizational behavior. According to Huber [17], organizational learning comprises components such as knowledge acquisition, information distribution, information interpretation, and organizational memory. Among these, knowledge acquisition can be further classified into forms like congenital learning (succession of knowledge of founders), experiential learning, vicarious learning (observation and imitation of successful routine by others), grafting (such as $\mathrm{M} \& \mathrm{~A}$ ), and searching and noticing.

Alternatively, Miner \& Mezias [18] classify organizational learning into learning by trial-and-error, inferential learning, vicarious learning, and generative learning.

Among these types of organizational learning, knowledge transfer is related to knowledge acquisition from other organizations and, specifically, to vicarious learning and 
grafting.

Next, a comparison of knowledge transfer theory and organizational learning theory as research domains indicates that these two domains are similar in two respects: (1) both theories deal with knowledge acquisition, knowledge sharing, and formation of routine, and (2) in both cases, individuals are regarded as central actors of knowledge acquisition and knowledge sharing activities.

In contrast, knowledge transfer theory and organizational learning theory differ in the following four ways.

First, their research perspectives are different. Organizational learning theory, in general, studies a relatively broader phenomenon that lasts for a longer duration [19]. The knowledge transfer theory generally deals with short-term micro-level phenomena instead.

For example, there are two main domains of knowledge transfer studies - adoption/diffusion of innovations and technology transfer [20]. In both domains, individual cases for diffusion or transfer of one single innovation or new technology have been studied.

At the same time, where research subjects of organizational learning theory include the phenomena at a deeper level, such as a change in the beliefs of an organization or an individual, they are out of scope for knowledge transfer theory. Nonetheless, knowledge transfer theory presumes these beliefs and objectives of organizations as given conditions for analysis.

Second, among the various types of knowledge acquisition processes, knowledge transfer theory mainly focuses on external learning and, especially, on transfer of knowledge through vicarious learning. In other words, other types of organizational learning, such as learning by trial-and-error, congenital learning, or grafting, are out of scope for knowledge transfer theory.

Third, and most important, knowledge transfer theory does not regard unlearning (discarding of obsolete routine), which is one of the main topics of organizational learning. In contrast, organizational learning theory, as compared to knowledge transfer theory, does not analyze the ramp-up stage, characterized by improvement of practices in the short term.

Finally, knowledge transfer theory regards the knowledge transfer process as a one-way serial process comprising four stages: initiation, implementation, ramp-up, and integration (e.g., [5]). In other words, it does not address the reversion to initiation stage after integration. Conversely, organizational learning theory regards organizational learning as a loop-like process (e.g., [21]).

This variation is due to a difference in the treatment of unlearning in these two research domains. According to organizational learning theory, unlearning is important as it marks the start of new learning, and adequate unlearning facilitates efficient learning in the next stage, thus forming a learning loop. Conversely, in knowledge transfer theory, knowledge transfer is a one-way process, where unlearning, which is the key factor forming the learning loop, is out of scope for the process.

\section{E. Limitation in Past Studies}

Until the previous section, a model of the entire knowledge transfer process and its components were analyzed by reviewing past studies on knowledge transfer and organizational learning. In this section, the four-stage knowledge transfer process model [5] is reviewed.

Szulanski [5] explains that the knowledge transfer process proceeds to the integration stage after the ramp-up stage, since a routine is formed after the outcome of the application of transferred knowledge is obtained. In other words, a behavior develops with the daily usage of transferred knowledge and improvement in practices. Then, the new practice is embedded into the institution with the sharing of meaning and behavior within the organization to form a new routine. Here, it is implied that recipients must modify and recreate knowledge through application to develop a routine [15], [22].

However, knowledge must be embedded into the routine before the stage of recreation (considering the definition by Levitt \& March [11] in II. A. above), and the components of routine (as in the definition above) must be established for organizations to formally apply the knowledge.

Alternatively, amendment of routine to reflect the results of usage of knowledge is also necessary. Routine and strategy should be amended to adapt to changes in the environment [15].

Therefore, in consideration of the discussion above, and to question the four-stage process model [5], the hypothesis below was formulated [6]:

"Hypothesis: Within the knowledge transfer process, the stage of knowledge usage (ramp-up) and that of routine formation (integration) are in a reciprocal relationship."

In the following chapters, the hypothesis above will is tested through the analysis of an actual case in the civil aviation domain.

\section{METHOD}

\section{A. Research Site}

For this study, the diffusion of air navigation technology called PBN (performance-based navigation) was selected as an event for knowledge transfer. Namely, the knowledge required by organizations to implement $\mathrm{PBN}$ needs to be transferred. PBN is one of the new air navigation technologies. PBN enables aircraft to fly on air routes with more flexibility than conventional navigation [23]. Moreover, PBN can help improve capacity of airports and airspace, safety, and accessibility to airports [23].

The main reason for the selection of PBN as the subject of this study is the presence of a broad range of stakeholders. The implementation of PBN involves air navigation service providers (ANSPs) which provide route design and air traffic control on these routes, aircraft operators such as airlines, and state regulators which regulates both ANSPs and operators. These stakeholders have to cooperate since their tasks are highly inter-dependent. This is because regulations and procedures for aircraft navigation must be standardized, as by its very nature, aircraft operation involves flights across state borders.

In addition, PBN is now being implemented by many 
states, under the leadership of International Civil Aviation Organization (ICAO) [24]. Therefore, it is possible to collect a wide range of data from various organizations and states.

\section{B. Data Collection and Analysis}

Personnel in charge of implementing PBN were interviewed to collect data on PBN implementation activities at the related organizations. Reflecting the range of stakeholders, as mentioned above, informants were selected from various organizations, including ANSP and regulators.

TABLE I: ATTRIBUTES OF INFORMANTS

\begin{tabular}{|c|c|c|c|}
\hline ID & Organization & Role of Informant & Remarks \\
\hline $\mathrm{I} 01$ & $\begin{array}{l}\text { Regulator } \\
\text { (Government) }\end{array}$ & $\begin{array}{l}\text { PBN } \\
\text { implementation at } \\
\text { state level }\end{array}$ & Recipient of ODA* \\
\hline $\mathrm{I} 02$ & $\begin{array}{l}\text { Regulator } \\
\text { (Government) }\end{array}$ & $\begin{array}{l}\text { PBN } \\
\text { implementation at } \\
\text { state level }\end{array}$ & Recipient of ODA \\
\hline $\mathrm{I} 03$ & $\begin{array}{l}\text { ANSP } \\
\text { (Government) }\end{array}$ & $\begin{array}{l}\text { Management of air } \\
\text { route design section }\end{array}$ & Recipient of ODA \\
\hline I04 & $\begin{array}{l}\text { Regional } \\
\text { international } \\
\text { organization }\end{array}$ & $\begin{array}{l}\text { Development of } \\
\text { technical standards }\end{array}$ & $\begin{array}{l}\text { Attending } \\
\text { international meeting } \\
\text { related to } \mathrm{PBN} \text { for } \\
\text { more than } 10 \text { years }\end{array}$ \\
\hline I05 & $\begin{array}{l}\text { ANSP } \\
\text { (Public } \\
\text { agency) }\end{array}$ & Air route design & $\begin{array}{l}\text { Attending } \\
\text { international meeting } \\
\text { related to } \mathrm{PBN} \text { for } \\
\text { approx. 1 year }\end{array}$ \\
\hline I06 & $\begin{array}{l}\text { UN specialized } \\
\text { organization }\end{array}$ & $\begin{array}{l}\text { Development of } \\
\text { technical standards, } \\
\text { including } \\
\text { organization of } \\
\text { technical meetings }\end{array}$ & $\begin{array}{l}\text { Secretary of } \\
\text { international meeting } \\
\text { related to PBN }\end{array}$ \\
\hline I07 & $\begin{array}{l}\text { ANSP } \\
\text { (Government) }\end{array}$ & Air route design & $\begin{array}{l}\text { Attending } \\
\text { international meeting } \\
\text { related to } \mathrm{PBN} \text { for } \\
\text { more than } 10 \text { years }\end{array}$ \\
\hline $\mathrm{I} 08$ & $\begin{array}{l}\text { ANSP \& } \\
\text { regulator } \\
\text { (Government) }\end{array}$ & $\begin{array}{l}\mathrm{PBN} \\
\text { implementation at } \\
\text { state level }\end{array}$ & $\begin{array}{l}\text { Attending } \\
\text { international meeting } \\
\text { related to } \mathrm{PBN} \text { for } \\
\text { approx. } 5 \text { years }\end{array}$ \\
\hline I09 & Airline & $\begin{array}{l}\text { Application of } \\
\text { operational } \\
\text { approval to } \\
\text { regulator \& internal } \\
\text { training }\end{array}$ & Major airline \\
\hline $\mathrm{I} 10$ & Airline & $\begin{array}{l}\text { Application of } \\
\text { operational } \\
\text { approval to } \\
\text { regulator \& internal } \\
\text { training }\end{array}$ & $\begin{array}{l}\text { Newly established } \\
\text { airline }\end{array}$ \\
\hline $\begin{array}{l}\text { I11 } \\
\text { thru } \\
\text { I14 }\end{array}$ & $\begin{array}{l}\text { General } \\
\text { aviation }\end{array}$ & $\begin{array}{l}\text { Application of } \\
\text { operational } \\
\text { approval to } \\
\text { regulator \& internal } \\
\text { training }\end{array}$ & $\begin{array}{l}\text { Interview conducted } \\
\text { as focus group }\end{array}$ \\
\hline $\mathrm{I} 15$ & $\begin{array}{l}\text { National } \\
\text { Agency } \\
\text { for ODA }\end{array}$ & $\begin{array}{l}\text { Technical support to } \\
\text { developing } \\
\text { countries on } \\
\text { implementation of } \\
\text { PBN }\end{array}$ & $\begin{array}{l}\text { Also with experience } \\
\text { in civil aviation }\end{array}$ \\
\hline
\end{tabular}

"Modified grounded theory approach" (M-GTA) was used to analyze the data [25]. In addition, publications and other public documents were referenced to support the interview data. The publications used for the study include ICAO's technical documents such as the PBN Manual [23] and other guidance material issued by ICAO regional offices.
Informants were selected such that the data covers a wide scheme of knowledge transfer processes related to PBN. The chosen informants belonged to public organizations [26], such as air navigation service providers, government regulators, international organizations, and private companies such as airlines. In all, fifteen informants (I01 through I15) were interviewed for the purpose of this study, covering two international organizations and six countries.

Attributes of informants are shown in Table I below. The number of informants (fifteen) was not pre-determined; it was determined during the analysis, upon reaching the situation of "theoretical saturation" [27], where new important concepts could not be identified.

Interviews were semi-structured and conducted between August 2012 and June 2013 in English or Japanese language. All the questions asked in the interview were related to the hypothesis of this study. Moreover, as far as possible, all the informant interviews were recorded (with their permission), except for I08 and I10, who denied permission to record the interviews. An interview with I11 through I14 was conducted as a focus group on their request.

It took a total of thirteen hours to conduct the interviews. The author then analyzed the responses to extract elements related to knowledge transfer and grouped mutually related elements into categories. As mentioned above, data collection and analysis was completed with the interview of I15, when it was determined that additional responses would not supplement any new information to the existing data.

In addition to the personnel interviews, the author also interviewed eight participants in a technical meeting on the implementation of PBN, organized by an ICAO regional office. The pool of eight participants covered seven countries and one international organization. Central questions were the same as in the main interviews; however, the comments of each participant were gathered in a short period of approximately ten minutes due to time constraints. This additional data helped to validate the data collected from the main interviews.

\section{RESUlts}

The data collected from the interviews were compared with the four-stage process model (Fig. 1), with a special focus on the order of the ramp-up (application of transferred knowledge) and integration (formation of routine) stages.

The analysis indicated the presence of both cases: one where application precedes formation of routine and the other where routine formation came before application. In addition, there were some cases with even more complex situations.

\section{A. Application First, Then Routine}

In some cases, the application of transferred knowledge preceded the formation of routine. These cases fit with the four-stage model [5].

I01 informed that he stepped into the issue of AIP (Aeronautical Information Publication: a publication issued by ICAO member states in order to publish information necessary for air navigation, as mandated by an Annex 15 to Convention on International Civil Aviation) without any 
prior establishment of regulation, although this is not a usual practice for government organizations. Note that some proper nouns in informants' comments have been replaced by common nouns in [ ] by the author for anonymity.

IOI "That day, [Name of State] did not have AIP. So my job is to write AIP instead of writing law because that day we did not have any regulation or air law. So we used AIP as a basic regulation."

In this case, the practice (the AIP) was used as a de-facto regulation. In addition, I01 explained the situation using an example of "swimming in river."

IOI "Normally in the natural life, rule is behind the practice. Every action, every life, I can say every operation is - I think let's say when we try to swim, we don't know how to swim and then some people - 10 people swim to the river, some lose their way, some swim faster, some swim slower and then we try to have a law or something like that. People need to swim on this current and this direction and please swim not too fast or something like that. So the regulation normally is behind the operation."

In summary, as I03 mentioned, actual needs for regulation are realized after application, in some cases.

I03 "Mostly in our case what happens is that we practice it and then we realize that we need a regulation to enforce what we are doing."

\section{B. Routine First, Then Application}

In contrast to the cases in item A above, there are cases where application is difficult without some kind of routine. One of the reasons for the need for routine (regulation) in organizations is to ensure accountability for their decisions and actions.

IO3 'But sometimes it's also difficult without rules because we are made to decide on ourselves to make decisions that we will be responsible for. If we have a regulation, at least you have a way to check whether what you are doing is good or bad."

This is especially the case when the organization in question is a public organization [28], such as a government body.

\section{Loop-Like Relationship between Application and Routine}

However, the situation is not as simple as that described above. Though I01 mentioned that application comes first, as in item A above, he also agreed that it is difficult to state which stage precedes the other.

IO1 "For PBN, according to the ICAO requirement, we need to have both together... But, we still have a problem. Sometime, it looks like egg and chicken."

One of the typical situations entails the introduction of some kind of initial routine, with an interim and/or a tentative status, before the initial application, and then, the amendment of initial routine based on the feedback from the actual application.
I08 "Ideally, regulations should be established first. However, for the implementation of PBN in my country, we conducted both of the establishment of regulations and actual implementation at the same time. This is to obtain the maximum benefit with the shortest time."

In some cases, application may take place first. For example, "trial operation" may be conducted before formal operation. [Name of two projects in the past] are the case. In these cases, arrival routes, with less risk in case of trouble, were established in an environment without terrain and under radar service. Then, the same technology was implemented in lower altitude where consequence is more severe than the arrival route."

This is same as for the medical science, "where animal experimentation is conducted before clinical trial. Even for the PBN in my country, we had experiences on the trial operation of similar technology. That worked well"

Evidently, it is sometimes difficult to identify hazards associated with a new technology before an actual implementation. By conducting a trial, such substantial hazards may be identified under conditions in which consequences in case of trouble might be tolerable.

Moreover, such trials serve another purpose. With the usage of trial status, public organizations can assume accountability for their initial actions. Trials with interim routines ensure better accountability than actions without any routine (regulations).

However, such interim routines cannot be made permanent directly. They must be formalized so that public organizations remain accountable on a long-term basis.

Though I08 shares his perspectives as a government officer, I09, a technical officer from an airline company in the same country as I08 further explains this situation from a different perspective. He pointed out that government bodies can conduct such trials for initial accountability, but need to change the trial status to formal operation to assume long-term accountability.

I09 "From the viewpoint of aircraft operation, nothing has changed between the trial operation and formal operation. Procedures for aircraft operation are the same. Maybe with the status of a trial, it would be difficult to expand the implementation for the government authority, although this is not problem for us as a private company. For government, it is difficult to speed up implementing something with trial status since they cannot carry out accountability. So, they have to establish the time line for the trial, then step into the formal operation."

As such, in the civil aviation domain, trial before formal operation is frequently conducted.

\section{DISCUSSION}

\section{A. Which Comes First}

Based on the findings above, both cases are likely. In some situations, organizations implement new technology without establishing a formal routine. This corresponds to the four-stage knowledge transfer model by Szulanski [5], where 
application precedes routine formation. In other cases, establishment of routine takes precedence over application. These cases exemplify another form of knowledge transfer process model, which is different from Szulanski [5].

As studied, a form of initial routine formation involves conducting a trial. In this case, interim routine, such as tentative rules and procedures, are established before application. This process is especially useful for public organizations [28], as motivation for public organizations is not related to economic benefits, but rather, to accountability. Thus, they cannot act without formal directives and/or regulations, which formalize their intentions. Trial operations can act as a means for public organizations to be accountable. Moreover, it is sometimes difficult for public organizations to amend their regulations. However, due to its interim nature, it is relatively easy for them to amend a trial routine into formal one. This is another benefit of trials.

Organizations also know that it is beneficial to conduct trials instead of formal operations before establishing a formal routine to minimize various risks. Moreover, it is to be noted that this case is applicable to not only public organizations but also any other formal organizations, including private companies, more or less.

\section{B. Modified Knowledge Transfer Process Model}

A "modified knowledge transfer process model" is proposed based on the findings of this study (Fig. 2). Fig. 2 is generally based on Szulanski's four-stage process model [5], but is different from it in terms of the relationship between the ramp-up and integration stages. In this modified model, first, transferred knowledge is integrated into an initial routine. For formal organizations, some form of routine, such as regulations and/or procedures, even with the interim/tentative status, is needed to conduct any activity. Then the routine is applied to the task and outcome is obtained, thereby improving its efficiency (ramp-up). In addition, the initial routine is amended based on the feedback from the application of transferred knowledge to the actual task.

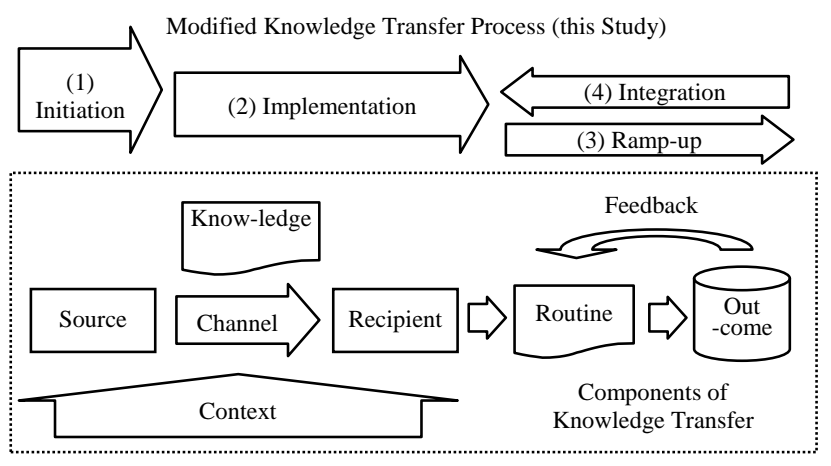

Fig. 2. Modified knowledge transfer process model.

In this model, the stage where outcome is improved with the application of routine is referred to as the ramp-up stage, and the one where routine is amended based on the feedback from the usage of knowledge is referred to as the integration stage. As such, the two activities, formation of routine and usage of knowledge, are in a reciprocal and mutual relationship.

This modified model will help better understand the knowledge transfer process, as total quality management (TQM) and other practices in current industry and business administration are mainly managed through cyclic processes [29].

\section{CONCLUSION}

This study reviews the four-stage knowledge transfer process model [5]. The analysis of actual knowledge transfer process in civil aviation domain indicates some deviation from the existing model. The analysis of data related to the implementation of PBN reveals that in the knowledge transfer process, some form of initial routine is established before the usage of transferred knowledge, and then, the interim routine is amended to a formal one based on feedback.

This study contributes to existing literature on knowledge transfer by proposing a "modified knowledge transfer process model" (Fig. 2) based on the analysis of civil aviation domain. Thus, this modified model is more sophisticated than the existing model [5] as it reflects the actual cases pertaining to an industry.

However, this study is still an explanatory qualitative research based on interviews with a limited number of informants. Therefore, the validity of the modified knowledge transfer process model should be tested by conducting additional empirical studies utilizing quantitative analysis.

\section{ACKNOWLEDGMENT}

I am grateful to Professor Makoto MATSUO (Hokkaido University) for his helpful comments and to the informants for providing valuable information on the topic of study.

\section{REFERENCES}

[1] P. F. Drucker, Post-Capitalist Society, Oxford: Butterworth Heinemann, 1993.

[2] R. M. Grant, "Toward a knowledge-based theory of the firm," Strategic Management Journal, vol. 17, winter special issue, pp. 109-122, 1999.

[3] W. Tsai, "Knowledge transfer in intraorganizational networks: Effects of network position and absorptive capacity on business unit innovation and performance," Academy of Management Journal, vol. 44, no. 5, pp. 996-1004, 2001.

[4] B. Kogut and U. Zander, "Knowledge of the firm, combinative capabilities, and the replication of technology," Organization Science, vol. 3, no. 3, pp. 383-397, 1992.

[5] G. Szulanski, "Exploring internal stickiness: Impediments to the transfer of best practice within the firm," Strategic Management Journal, vol. 17, winter special issue, pp. 27-43, 1996.

[6] Y. Nakanishi, "The process and constructs of knowledge transfer: Reciprocity between knowledge usage and formation of routine, in Japanese," Journal of Business Management, vol. 31, pp. 27-38.

[7] G. Szulanski, "The process of knowledge transfer: A diachronic analysis of stickiness," Organizational Behavior and Human Decision Processes, vol. 82, no. 1, pp. 9-27, 2000.

[8] L. Argote, P. Ingram, J. M. Levine, and R. L. Moreland, "Knowledge transfer in organizations: learning from the experience of others," Organizational Behavior and Human Decision Processes, vol. 82, no. 1, pp. 1-8, 2000.

[9] R. V. Wijk, J. J. P. Jansen, and M. A. Lyles, "Inter- and intra-organizational knowledge transfer: A meta-analytic review and assessment of its antecedents and consequences," Journal of Management Studies, vol. 45, no.4, pp. 830-853, 2008.

[10] E. D. Darr and T. R. Kurtzberg, "An investigation of partner similarity dimensions on knowledge transfer," Organizational Behavior and Human Decision Processes, vol. 82, no. 1, pp. 28-44, 2000. 
[11] B. Levitt and J. G. March, "Organizational learning," Annual Review of Sociology, vol. 14, pp. 319-340, 1988.

[12] L. P. Nordtvedt, B. L. Kedia, B. K. Datta, and A. A. Rasheed, "Effectiveness and efficiency of cross-border knowledge transfer: An empirical examination," Journal of Management Studies, vol. 45, no. 4, pp. 714-744, 2008.

[13] I. Nonaka and H. Takeuchi, The Knowledge Creating Company, NY: Oxford University Press, 1995.

[14] M. H. Zack, "Managing codified knowledge," Sloan Management Review, vol. 40, no. 4, pp. 45-58, 1999.

[15] N. Foss and T. Pedersen, "Transferring knowledge in MNCs: The role of sources of subsidiary knowledge and organizational context," Journal of International Management, vol. 8, no. 1, pp. 49-67, 2002.

[16] B. Hedberg, "How organizations learn and unlearn," in Handbook of Organizational Design, P. C. Nystrom and W. S. Starbuck Eds. New York: Oxford University Press, 1981, vol. 1, pp. 3-27.

[17] G. P. Huber, "Organizational learning: The contributing processes and the literatures," Organization Science, vol. 2, no. 1, pp. 88-115, 1991.

[18] A. S. Miner and S. J. Mezias, "Ugly duckling no more: Pasts and futures of organizational learning research," Organization Science, vol. 7, no. 1, pp. 88-99, 1996.

[19] F. Ando, Organizational Learning and Map in Organization (Soshiki-Gakusho to Soshikinai-Chizu), Tokyo: Hakuto-Shobo, 2001.

[20] E. D. Darr, L. Argote, and D. Epple, "The acquisition, transfer, and depreciation of knowledge in service organizations: Productivity in franchises," Management Science, vol. 41 no. 11, pp. 1750-1762, 1995

[21] C. Argyris and D. A. Schon, Organizational learning: A theory of Action Perspective, CA: Addison-Wisley, 1978.

[22] P. Attewell "Technology diffusion and organizational learning: The case of business computing," Organization Science, vol. 3, no. 1, pp. 1-19, 1992.

[23] Performance-Based Navigation (PBN) Manual (Doc 9613), 4th ed, Montreal: International Civil Aviation Organization (ICAO), 2013.

[24] ICAO. (2013). ICAO Performance Based Navigation Programme. [Online]. Available: http://www.icao.int/safety/pbn/

[25] Y. Kinoshita, Practices of Grounded-Theory Approach: Introduction to Qualitative Research (Grounded Theory Approach no Jissen: Shitsuteki-Kenkyu e no Sasoi), Tokyo: Koubundou, 2003.
[26] J. L. Perry and H. G. Rainey, "The public-private distinction in organization theory: A critique and research strategy," Academy of Management Review, vol. 13, no. 2, pp. 182-201, 1988.

[27] B. G. Glaser and A. L. Strauss, The Discovery of Grounded Theory: Strategies for Qualitative Research, Chicago, IL: Aldine, 1967.

[28] H. G. Rainey, R. Backoff, and C. H. Levine, "Comparing public and private organizations," Public Administration Review, vol. 36 no. 2, pp 233-244, 1976

[29] M. Matsuo and J. Nakahara, "The effects of the PDCA cycle and OJT on workplace learning," The International Journal of Human Resource Management, vol. 24, no. 1, pp. 195-207, 2013.

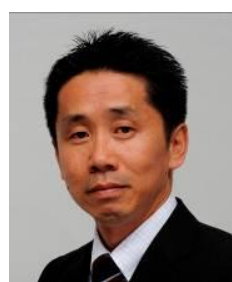

Yoshinobu Nakanishi was born in Nara, Japan, in 1969. He has a bachelor of science in mathematics and a master of arts and sciences degree. He is now a $\mathrm{Ph} . \mathrm{D}$. candidate at Graduate School of Business Administration, Kobe University as of 2013. His research domain in management studies includes organizational learning and experiential learning by individuals and community of practice. He has been working in the civil aviation domain for nearly 20 years, and is involved in technologies for aircraft operations. He is an advisor to the Instrument Flight Procedure Panel (IFPP) organized by International Civil Aviation Organization (ICAO). He also led the Training Working Group of IFPP as its rapporteur and accomplished the development of "Quality Assurance Manual for Flight Procedure Design, Volume 2 Flight Procedure Designer Training" (published in 2009). He is still working as a rapporteur for IFPP's Quality Assurance Working Group, leading the discussions for the development of regulatory framework and organizational development for flight procedure design organizations. He also conducts research as a visiting researcher at Japan Aerospace Exploration Agency (JAXA). Mr. Nakanishi is a member of Japan Academy of Business Administration, Japan Association of Administrative Science, The Academic Association for Organizational Science, The Japanese Psychological Association, The Japanese Association of Industrial/Organizational Psychology, and Japanese Cognitive Science Society. 